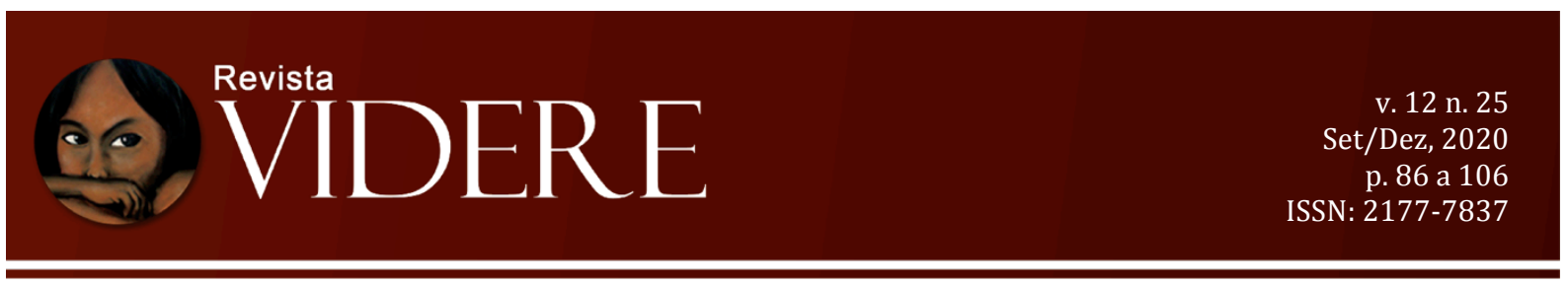

\title{
ENQUANTO NO BRASIL PAIS BUSCAM SEUS DIREITOS SOBRE A INCLUSÃO ESCOLAR NO MINISTÉRIO PÚBLICO, NA EUROPA NÃO PRECISAM LITIGAR.
}

\author{
WHILE IN BRAZIL PARENTS SEEK THEIR RIGHTS TO SCHOOL INCLUSION IN \\ THE PUBLIC SERVICE, IN EUROPE THEY DO NOT NEED TO LITIGATE. \\ MIENTRAS QUE EN BRASIL LOS PADRES BUSCAN SUS DERECHOS SOBRE LA \\ INCLUSIÓN ESCOLAR EN EL MINISTERIO PÚBLICO, EN EUROPA NO NECESITAN \\ LITIGAR.
}

Monaliza Ehlke Ozorio Haddad Doutora em Educação pela Universidade de Évora monalizahaddad@gmail.com

Orcid ID: https://orcid.org/0000-0003-0485-9202

\author{
Pedro Garrido Rodríguez Correio \\ Doctor por la Universidadd de Salamanca \\ Salamanca - Espanha \\ pegarro@usal.es \\ Orcid ID: https://orcid.org/0000-0001-8154-6627
}

Resumo: Este artigo é uma análise sobre a legislação brasileira no que tange os direitos dos alunos com Necessidades Educativas Especiais - NEE, de forma mais específica na busca pelo professor de apoio. Como cidadãos, temos Direitos Humanos adquiridos conforme a legislação e de acordo com as Políticas Públicas Educacionais, mas na prática, alguns pais precisam recorrer à justiça para terem os seus direitos atendidos. Os documentos analisados nesta investigação se referem a um estudo de caso de uma aluna com o diagnóstico da Síndrome do X Frágil e do Transtorno do Espectro Autista - TEA. A metodologia utilizada foi um estudo de caso, com a análise do discurso, numa investigação qualitativa e interpretativa sobre os dados obtidos. A pergunta norteadora desta investigação é: "Por que as famílias brasileiras precisam recorrer ao Ministério Público em busca de direitos adquiridos, enquanto na Europa não nos deparamos com a mesma situação?”

Palavras chaves: Direitos humanos. Políticas públicas educacionais. Inclusão escolar. Necessidades educativas especiais. 


\begin{abstract}
This article is an analysis of the brazilian legislation regarding the rights of students with Special Educational Needs, more specifically in the search for the support teacher. As citizens, we have human rights acquired in accordance with the law and in accordance with the Public Educational Policies, but in practice, some brazilian parents have to go to court to have their rights met. The documents analyzed in this investigation refer to a case study of a student with the diagnosis of Fragile X Syndrome and Autistic Spectrum Disorder - TEA. The methodology used was a case study, with discourse analysis, in a qualitative and interpretative investigation about the obtained data. The guiding question of this research is: "Why do Brazilian families need to go to the Public Prosecution Service for acquired rights, while in Europe we are not facing the same situation?"
\end{abstract}

Key words: Human rights. Educational public policies. School pnclusion. Special educational needs.

Resumen: Este artículo es un análisis sobre la legislación brasileña en lo que se refiere a los derechos de los alumnos con Necesidades Educativas Especiales (NEE), de forma más específica en la solicitud del profesor de apoyo. Como ciudadanos, tenemos Derechos Humanos adquiridos conforme a la legislación y de acuerdo con las Políticas Públicas Educativas, pero en la práctica, algunas familias necesitan recurrir a la justicia para ver atendidos sus derechos. Los documentos analizados en esta investigación se refieren a un estudio de caso de una alumna diagnosticada con el Síndrome de X Frágil y Trastorno de Espectro Autista (TEA). La metodología empleada fue un estudio de caso, con el análisis del discurso en una investigación cualitativa e interpretativa sobre los datos obtenidos. La pregunta orientadora de esta investigación es: ¿por qué las familias brasileñas necesitan recurrir al Ministerio Público en busca de derechos adquiridos, mientras que en Europa no nos encontramos con la misma situación?

Palabras clave: Derechos Humanos. Políticas públicas educativas. Inclusión escolar. Necesidades educativas especiales.

\title{
1 Introdução
}

Quando o assunto é inclusão escolar, nos deparamos primeiramente com os Direitos Humanos dos cidadãos e sentimos esta situação de maneira intensa no Brasil no que se refere a busca de direitos. Existem muitas leis sobre essa temática, porém, muitos pais sentem a necessidade em buscar a legitimidade da legislação no Ministério Público.

A escolha por essa investigação é devido aos inúmeros casos de famílias que recorrem ao meu Instituto, nominado como Instituto Aprendizagem e Desenvolvimento - IAD no Brasil, em relação aos direitos educacionais dos seus filhos voltados a política educacional brasileira. As questões dos direitos dos filhos sempre é um assunto muito questionado. Ainda mais por sabermos que as famílias são essenciais para que a inclusão aconteça de forma satisfatória, inicialmente por aceitarem o diagnóstico de seus filhos e posteriormente por trabalhar de forma integrada e em parceria com a escola em que seu filho está matriculado. 
Essa referida investigação irá se delimitar em um estudo de caso em que a família recorreu aos tribunais solicitando o professor de apoio para a sua filha durante o período escolar. Neste sentido, compreendemos que, "o homem necessita extrair da natureza, ativa e intencionalmente, os meios de sua subsistência. Ao fazer isso, ele inicia o processo de transformação da natureza, criando o mundo humano - o mundo da cultura." (Saviani, 2003, p $11)$.

Para melhor compreendermos este aspecto, vamos recorrer as legislações mais específicas desta situação posta e neste sentido, iremos abordá-las como uma forma explicativa do que se refere aos direitos no decorrer desta investigação.

\section{Metodologia da investigação}

Esta pesquisa iniciou com o Estado da Arte, tendo como base nas legislações atuais sobre a temática, buscando também as principais investigações no domínio da inclusão educativa das crianças e adolescentes.

Com o objetivo de analisar os direitos sobre a inclusão escolar, abordamos um problema para investigar: Qual o motivo que os pais recorrem ao Ministério Público em busca dos direitos para os filhos no que se refere a Inclusão Escolar, principalmente na solicitação de professor de apoio para seus filhos?

Considerando que a questão norteadora da pesquisa se enquadra no paradigma da investigação interpretativa e qualitativa, o que torna um estudo interpretativo é uma questão de foco intencional e qualitativa, é em relação a ênfase na interpretação, considerando os instrumentos necessários para a investigação, segundo (Erickson, 1986).

Flick (2004) nos esclarece que "a pesquisa qualitativa é orientada para análise de casos concretos em sua particularidade temporal e local, partindo de expressões e atividades das pessoas em seus contextos locais.” (Flick, 2004, p. 28).

Esta investigação é composta por um estudo de caso, para Yin (2005), "estudo de caso é uma investigação empírica, que investiga um fenômeno contemporâneo dentro de seu contexto da vida real" um método que abrange o planejamento, técnicas de coleta de dados e análise dos mesmos.

A fonte de dados desta investigação foi uma família que tem uma filha com diagnóstico da Síndrome do X Frágil - SXF e Transtorno do Espectro Autista - TEA e busca o professor de apoio para acompanhá-la durante as aulas auxiliando nas questões pedagógicas. Portanto, esta pesquisa insere-se em um trabalho interpretativo uma vez que pretende 
descrever de forma interpretativa os direitos sobre a inclusão escolar dos alunos e compreender o motivo que as famílias recorrem à justiça, solicitando um profissional para apoiar seus filhos no quesito da inclusão escolar.

Um dos aspectos importantes é que o investigador consiga compreender sobre os participantes que constituem da sua investigação, principalmente em relação onde estes estão inseridos na sociedade, conforme Guerra (2016) nos explicita,

Do ponto de vista qualitativo, considera-se que os atores interpretam as situações, concebem estratégias, mobilizam recursos e agem em função dessas interpretações. No contexto do paradigma interpretativo, o objeto de análise é formulado em termos de acção, acção essa que abrange o comportamento físico e os significados lhe são atribuídos pelo actor e por aqueles com quem interagem entanto, tradicionalmente, e do ponto de vista sociológico, o objeto da investigação social interpretativa é o significado dessa acção e não o comportamento em si próprio (Guerra, 2006, p 17).

A presente investigação tem como objetivo geral compreender o motivo que as famílias, mesmo tendo direitos adquiridos na legislação, ainda recorrem a justiça para a busca de Inclusão Escolar para seus filhos.

Partindo do objetivo geral, o artigo pretende também esclarecer nos objetivos específicos:

1 - Identificar a legislação existente no Brasil que ampare a Inclusão Escolar;

2 - Compreender como a família e a escola percebem a inclusão escolar no processo de escolarização;

3 - Analisar os pareceres dos profissionais quanto ao pedido de professor de apoio para auxiliar nas dificuldades pedagógicas encontradas;

Em síntese, a centralidade deste estudo é compreender o que levam os pais a recorrerem a justiça, em busca de inclusão escolar dos seus filhos, principalmente no que tange o auxílio do professor de apoio durante as aulas.

\section{Aspectos sociais e culturais na busca pelos direitos humanos}

A escola é considerada um espaço social, que tem interferência no desenvolvimento das práticas pedagógicas em Direitos Humanos. Além dela, temos outros espaços sociais que podem ser considerados como locais que buscam o desenvolvimento de práticas de respeito às diversidades e aos Direitos Humanos. 
Neste sentido compreendemos que a finalidade da Educação em Direitos Humanos é a formação para a vida e para a convivência social e cultural, no exercício cotidiano dos Direitos Humanos como forma de vida e de organização social, política, econômica e cultural.

Candau nos dá a sua contribuição, onde nos leva a uma reflexão que a educação é vista (...) como transmissão de conhecimentos atualizados sobre os Direitos Humanos. Não se problematiza, nem se articula adequadamente a questão dos Direitos Humanos com as diferentes concepções pedagógicas, procurando-se enfatizar aquelas que melhor sintonizariam com a perspectiva dos Direitos Humanos que se quer promover. (Candau, 2008, p. 288)

O Plan de Acción, Programa Mundial para La Educación em Derechos Humanos (2006), nos esclarece que,

La educación em derechos humanos puede definirse como un conjunto de actividades de educación, capacitación y difusión de información orientadas a crear una cultura universal de los derechos humanos. Una educación integral em derechos humanos no sólo proporciona conocimientos sobre los derechos humanos y los mecanismos para protegerlos, sino que, además, transmite lãs aptitudes necesarias para promover, defender y aplicar los derechos humanos em la vida cotidiana. La educación em derechos humanos promueve lãs actitudes y el comportamiento necesarios para que se respetenlos derechos humanos de todos los miembros de la sociedade (2006 p. 2).

Quando fazemos referência a educação em Direitos Humanos, falamos em uma educação voltada para a cidadania, para as questões sociais e culturais em busca por direitos. Segundo Pando e seus colaboradores, "se aceitamos que os Direitos Humanos, pelo menos a sua concretização e reconhecimento, que é o que os torna operativos, são fruto de um processo histórico, são criados, constroem-se ou reivindicam a resolução de problemas e necessidades reais dos cidadãos e podem ser, e lamentavelmente são, muitas vezes, reelaborados, desnaturalizados e manipulados para servir o poder, não sendo mais aceitável considerá-los como uma série de princípios ou ideias intemporais e descontextualizadas, temos de assumir que a história social, política ou cultural está obrigada a prestar-lhes mais atenção do que o fez até agora, com honrosas exceções, e o brindou, resultando muito útil para determinar a origem e o desenvolvimento inicial de tais direitos e também para conhecer como estes vão sofrendo transformações de forma paralela à aparição de novas demandas de cidadania ou em função do surgimento de necessidades no passado inéditas" (Pando Ballesteros, 2016, p.17).

Quando buscamos na literatura o que temos em relação aos Direitos Humanos no Brasil, recorremos ao Plano Nacional de Educação em Direitos Humanos (PNEDH, 2018, p. 
11) e nos deparamos com a seguinte afirmação sobre o processo educativo, considerado (...) dever dos governos democráticos garantir a educação de pessoas com necessidades especiais, a profissionalização de jovens e adultos, a erradicação do analfabetismo e a valorização dos educadores da educação, da qualidade da formação inicial e continuada, tendo como eixos estruturantes o conhecimento e a consolidação dos Direitos Humanos.

O PNEDH (2012, p. 25) nos esclarece que (...) a educação é compreendida como um direito em si mesmo e um meio indispensável para o acesso a outros direitos. A educação ganha, portanto, mais importância quando direcionada ao pleno desenvolvimento humano e às suas potencialidades, valorizando o respeito aos grupos socialmente excluídos. Essa concepção de educação busca efetivar a cidadania plena para a construção de conhecimentos, o desenvolvimento de valores, atitudes e comportamentos, além da defesa socioambiental e da justiça social.

No Parecer $n^{\circ}$ 08/2012, que apresenta as Diretrizes Nacionais para a Educação em Direitos Humanos, nas últimas décadas, tem-se assistido a um crescente processo de fortalecimento da construção da Educação em Direitos Humanos no país, por meio do reconhecimento da relação indissociável entre educação e Direitos Humanos. Desde então, foi adotada uma série de dispositivos que visam a proteção e a promoção de direitos de crianças e adolescentes; a educação das relações étnico-raciais; a educação escolar quilombola; a educação escolar indígena; a educação ambiental; a educação do campo; a educação para jovens e adultos em situação de privação de liberdade nos estabelecimentos penais, as temáticas de identidade de gênero e orientação sexual na educação; a inclusão educacional das pessoas com deficiência e a implementação dos Direitos Humanos de forma geral no sistema de ensino brasileiro.

Colaborando com a nossa investigação, recorremos a Maldonado (2004, p. 24) que nos esclarece que a finalidade da Educação em Direitos Humanos é a formação para a vida e para a convivência, no exercício cotidiano dos Direitos Humanos como forma de vida e de organização social, política, econômica e cultural. Devido a este aspecto que buscamos uma escola cada vez mais inclusiva para os alunos com NEE. 


\section{Família - um alicerce importante para a Inclusão Escolar dos seus filhos, numa perspectiva de totalidade e do desenvolvimento cultural e social.}

Quando pensamos em desenvolvimento humano, temos três agentes envolvidos neste processo: a família, a escola e o aluno. A família obtém muitos dados e conhece melhor sobre o desenvolvimento de seu filho do que ele próprio, tendo um potencial importante e que vai auxiliar em todo o processo educativo, valorizando o diálogo e a interação social. Segundo Dessen e Polonia, 2007, p. 22, a família é vista como:

(...) primeira mediadora entre o homem e a cultura, a família constitui a unidade dinâmica das relações de cunho afetivo, social e cognitivo que estão imersas nas condições materiais, históricas e culturais de um dado grupo social. Ela é a matriz da aprendizagem humana, com significados e práticas culturais próprias que geram modelos de relação interpessoal e de construção individual e coletiva. Os acontecimentos e as experiências familiares propiciam a formação de repertórios comportamentais, de ações e resoluções de problemas com significados universais (cuidados com a infância) e particulares (percepção da escola para uma determinada família). Essas vivências integram a experiência coletiva e individual que organiza, interfere e a torna uma unidade dinâmica, estruturando as formas de subjetivação e interação social. E é por meio das interações familiares que se concretizam as transformações nas sociedades que, por sua vez, influenciarão as relações familiares futuras, caracterizando-se por um processo de influências bidirecionais, entre os membros familiares e os diferentes ambientes que compõem os sistemas sociais, dentre eles a escola, constituem fator preponderante para o desenvolvimento da pessoa.

Desta forma, a família tem um papel importantíssimo no que se refere a interação do seu filho no mundo que está envolvido, por questões culturais e sociais. Como a família é o primeiro contato da criança com o mundo, é ela quem vai fazer com que o processo de interação ocorra primeiramente.

A segunda instância de interação geralmente é a escola e esta é mais alargada e sofre influências significativas, principalmente em relação ao acesso cultural que o aluno vai encontrar ao ter acesso a outras alternativas no que se refere a concepção de cultura.

Considerando os fenômenos sociais para a humanidade, podemos pensar na educação enquanto um direito humano numa perspectiva de concepção que envolve,

[...] A educação é parte de um conjunto de interações e de interconexões recíprocas e não pode ser dissociada dele, tratada isoladamente. É parte de um todo, porém este todo sendo um processo, só a noção de totalidade permite compreender a inter-relação de cada parte com as demais, pois não se trata de um todo estático, e sim de uma realidade total em movimento, na qual a alteração de qualquer elemento influi sobre todos os demais. A noção de totalidade introduz uma nova percepção de fatos sociais, como são as campanhas de alfabetização e de educação de adultos. Porque coloca estes 
fatos à luz do princípio de totalidade e mostra como repercutem necessariamente sobre todos os aspectos da sociedade, ao mesmo tempo em que as mudanças ocorridas nos demais campos, como efeito daquelas campanhas, revertem sobre a compreensão, à valoração e o curso destas mesmas campanhas. (Pinto, 1989 p. 51-52).

Colaborando com este pensamento, Saviani (2005), afirma que a origem da educação coincide com a origem do homem, já que ele não nasce com sua existência garantida pela natureza, precisa produzi-la e dominá-la e, para tanto, precisa dos conhecimentos produzidos socialmente pelos homens, como "conhecimento sensível, intuitivo, afetivo, conhecimento intelectual, lógico, racional, conhecimento artístico, estético, conhecimento axiológico, conhecimento religioso e, mesmo, conhecimento prático e conhecimento teórico (p.15)”.

Portanto, o desenvolvimento humano encontra-se atrelado a vários outros aspectos, pois quando nos referimos ao desenvolvimento precisamos pensar na totalidade.

Ainda temos os aspectos culturais e familiares que se envolvem com outras culturas no processo de interação, sendo que as famílias estão sempre muito presentes no processo educativo por compreenderem que este é o caminho para o desenvolvimento de seus filhos.

\section{O papel da escola inclusiva no desenvolvimento dos alunos com Necessidades}

\section{Educativas Especiais - NEE}

Quando nos reportamos a educação inclusiva, temos que ter em mente a busca por uma escola com equidade em justiça, ou seja, uma escola voltada a inclusão cultural, social e pedagógica, garantindo sempre que seja considerada uma escola de qualidade, uma escola voltada a democracia e onde o aluno receba tudo aquilo que ele precisa. Ainscow (2005) nos indica que a escola deve ser percebida como:

Las escuelas saben más de lo que utilizan y de que el punto de partida lógico para el desarrollo em pieza, por lo tanto, por um detallado análisis de lãs prácticas existentes. Esto permite identificar y compartir lãs buenas prácticas, mientras que, al mismo tiempo, se pone atención sobre lãs maneras de trabajar que pueden estar creando barreras a la participación y aprendizaje de algunos estudiantes. Sin embargo, como yahe destacado, el centro de atención de tales enfoques no sólo es lapráctica. También es el pensamiento que se halla detrás de estas maneras de trabajar. La recogida y trabajo com lãs pruebas dentro de una escuela proporciona um medio para que afloren premisas asumidas que pueden ser la causa de lãs barreras que algunos aprendices experimentan. (p.12).

Nas escolas, nos deparamos com grupos heterogêneos e, portanto, o contato dos alunos uns com os outros é considerado muito enriquecedor, afinal a diversidade é 
considerada uma mais valia. Ao compreender essa diversidade podemos considerar um ponto de partida para a inclusão.

A escola tem como função favorecer o acesso dos alunos nas instituições escolares que também são consideradas sociais, devido as inúmeras questões multiculturais que nos deparamos cotidianamente nesse ambiente, aonde as suas estruturas no âmbito escolar vêm contribuir ao processo de interação e também favorecer o desenvolvimento pessoal dos alunos matriculados.

Temos que considerar que somos todos diferentes nos aspectos biológicos, físicos, sociais e também culturais, temos nossas heranças culturais, mas é nas instituições escolares que recebemos novos valores, hábitos e atitudes. Quando não consideramos estes aspectos como um fator significativo, negamos a humanidade o direito a sentir-se incluído e pertencente a um contexto social, ou seja, na sociedade.

O papel do professor é garantir o respeito e as diferenças individuais e desenvolver um trabalho de acordo com os alunos que encontram se matriculados, considerando-os com respeito ao ritmo de desenvolvimento que é diferente uns dos outros.

O princípio de igualdade em relação aos direitos deve ser sempre respeitado por todos, sendo a escola um local onde não se pode conceder e admitir distinções nenhumas em relação a raças, línguas, gênero e capacidades.

Não podemos nos limitar apenas a inclusão escolar e sim buscarmos sempre a inclusão social, sendo esta considerada mais ampla e que necessita de um olhar diferenciado. Em 1999, a UNESCO (p. 59), já mencionava que a educação precisava ser considerada na perspectiva,

"La educación puede ser um factor de cohesión social si procura transformar la diversidade nun factor positivo de entendimiento mutuo entre los individuos y los grupos humanos y al mismo tiempo evita ser (ella misma) un fator de exclusión social".

$\mathrm{Na}$ inclusão buscamos o acesso ao conhecimento a todos os alunos matriculados independentemente se o aluno apresenta uma Necessidade Educativa Especial - NEE ou não. A escola, nesta visão, busca o processo inclusivo cotidianamente, sem distinção e em todas as suas ações. A inclusão pode ser considerada como um processo comparado ao caminhar, não algo pronto, pois as adequações precisam sempre considerar as características dos seus alunos, respeitando uma educação diferenciada, atendendo o conhecimento que o aluno tem e ampliando este acesso ao conhecimento com: metodologia adequada, recursos necessários para tal apropriação do conhecimento, adaptações do currículo e o conhecimento do 
professor, que deve sempre estar compreendendo melhor o seu aluno e ainda favorecendo o desenvolvimento deles de forma integral.

$\mathrm{Na}$ Espanha, um dos países da União Européia, nos deparamos com o lema que: "somos todos iguais e todos diferentes". Nesta perspectiva temos sempre que considerar que os programas de educação são importantes neste processo, bem como a participação das famílias que precisam estar vinculadas ao processo educativo de seus filhos para entenderem como ocorre este processo em relação principalmente ao acolhimento escolar em relação ao processo inclusivo.

Neste sentido, na perspectiva educativa, o professor tem o objetivo de atender as necessidades percebidas dos alunos em um processo para integrá-los da melhor forma possível, para assim, ele atingir o seu melhor desempenho e tendo as suas necessidades atendidas no que se refere a apropriação dos conhecimentos. Em algumas situações, percebese que é necessário um tempo maior no âmbito escolar para alguns alunos, para que se efetive o processo de ensino e de aprendizagem, mas este fator está altamente atrelado ao conhecimento individualizado que damos a cada aluno.

Quando pensamos em estratégias necessárias, pode ser que em alguns casos precisaremos contar com intervenções de outros profissionais, dos professores de apoio, ainda com medidas adaptativas curriculares individualizadas e até mesmo com programas de diversificação curricular.

Também podemos ter em mente que, em determinadas situações escolares, os alunos podem se deparar com dificuldades e de apoio. Quando nos reportamos ao assunto apoio, o que nos vêm em mente é o professor de apoio, que é um direito assegurado em legislação.

Quando nos referimos à inclusão, temos que pensar que o trabalho envolve todos os membros da escola, considerando que a articulação entre os gestores e profissionais é importantíssima. Realizando um trabalho em conjunto, respeitando os conhecimentos de suas áreas para potencializar cada vez mais a inclusão, desenvolvem desta forma as habilidades e conhecimentos do aluno como uma pessoa ativa no processo de ensino e de aprendizagem.

Quando a escola percebe que as famílias são essenciais para este processo, ainda há uma mais valia e somente desta forma pode-se propor novas estratégias, aliando a família que tem um conhecimento importantíssimo sobre o desenvolvimento de seus filhos, e a escola que tem os conhecimentos sobre as questões pedagógicas. Juntas vão auxiliar no desenvolvimento e na aprendizagem dos alunos nos ambientes acadêmicos e no cotidiano. 
As famílias demonstram que têm preocupações referentes as questões educativas e, neste sentido, é importante traçar o objetivo de estarem caminhando juntas, favorecendo a participação de todos através do fortalecimento das relações.

Portanto, a escola e o professor são visto como mediadores do processo de ensino e de aprendizagem, e neste sentido recorremos a Miranda (1989, p. 134) que nos explica que a socialização no ambiente escolar é "um processo de socialização qualitativamente distinto, passando a internalizar novos conteúdos, padrões de comportamento e valores sociais. Será submetida a novos processos de internalização da realidade social, pela mediação de novos veículos sociais".

Pujolás (2006), destaca "La escolarización de todo el alumnado en aulas ordinarias y, no solo su escolarización, sino también su participación em lãs actividades de la vida escolar".

Neste sentido, o cotidiano escolar favorece o desenvolvimento e a aprendizagem dos alunos no que se refere aos conhecimentos. Não existe a possibilidade de termos alunos fora dos ambientes escolares, sem estarem trabalhando com seus pares no que se refere ao desenvolvimento cognitivo, social e psicológico. É neste contexto que os alunos aprendem a se relacionar uns com os outros e vão demonstrando as competências básicas para tal relacionamento social, emocional e pedagógico.

Ao atendermos as necessidades educativas dos alunos com programas de aprendizagem, facilitamos o conhecimento e indicamos como é o processo da organização do espaço escolar, da integração dos alunos com todos. Assim estamos valorizando o autoconhecimento e a identidade de cada aluno em relação aos aspectos pessoais e culturais. Em relação às famílias podemos buscar o fortalecimento e a colaboração das mesmas nos ambientes escolares, favorecendo o diálogo entre escolas e famílias.

A inclusão educativa é um processo que tem a aprendizagem dos alunos como um objetivo a ser alcançado, mas nos deparamos, nas instituições escolares, com alunos com diferentes diagnósticos. Devido a este fator, temos que considerar o aluno de forma individual e primar o desenvolvimento do mesmo de forma global, ou seja, na totalidade.

Quando nos referimos à inclusão temos a necessidade em conhecer as características dos alunos, estilos de aprendizagem de cada um, como se efetiva este processo, levá-los aos conhecimentos globais e analisar as medidas indicadas para o desenvolvimento, considerando as características indicadas por todo o grupo que desenvolve trabalhos com este aluno. Desta forma estaremos buscando uma cooperação entre todos os envolvidos, com todos sentindo-se importantes e pertencentes neste processo. 
Temos ainda que valorizar e fortalecer o diálogo entre professor e aluno, bem como a igualdade no tratamento, sem nenhuma discriminação, para superar as dificuldades enfrentadas no processo evolutivo dos alunos, auxiliando-os de forma eficaz no que se refere a melhoria no processo de aprendizagem.

\section{Como é o sistema educativo no Brasil? Neste momento atual nos deparamos com uma dualidade em relação as instituições de ensino}

Contextualizando o cenário educacional, no Brasil os alunos permanecem nas escolas um total de quatro horas diárias, totalizando duzentos dias letivos e oitocentas horas anuais, conforme estabelecido em um calendário anual. $\mathrm{O}$ ano letivo inicia em fevereiro, com uma pausa de quinze dias em julho e termina no mês de dezembro.

Para o Ensino Regular, nos anos iniciais, os alunos contam com uma professora que rege as disciplinas de Língua Portuguesa, Ciências, História, Geografia e Matemática e os professores para Educação Física e Artes são professores especializados nesta área de atuação.

No que se refere aos anos finais do Ensino Regular, contamos com um professor para cada área de atuação e as aulas são divididas em cinquenta minutos para cada disciplina, totalizando cinco ou seis disciplinas diárias.

Quando nos referimos ao professor de apoio para os alunos incluídos, são professores que acompanham o aluno no Ensino Regular, permanecendo na mesma sala de aula que o professor regente, porém, auxiliando o aluno de forma mais direta e muitas vezes até adaptando os matérias para que o aluno incluso possa se apropriar dos conhecimentos trabalhados na sala de aula.

Ainda no Brasil temos uma dualidade quando o tema são as instituições de ensino: temos as Escolas Especiais separadas das Escolas de Ensino Regular ou Fundamental, onde nem todos os alunos com Necessidades Educativas Especiais são atendidos no Ensino Regular; dependendo do grau de complexidade dos seus diagnósticos e das questões cognitivas que apresentam. Quando estas questões são muito significativas, existe a indicação aos alunos frequentarem as Escolas Especiais.

As Escolas Especiais apresentam um número menor de alunos por sala de aula e ainda um trabalho voltado às questões mais individualizadas e com ensinamentos voltados a autonomia e cotidiano social. Além das funções expostas é uma modalidade que ensina 
questões que podem ser importantes para a busca de profissionalização quando maiores de idade.

\section{Legislações específicas do Brasil no que se refere à Políticas Públicas Educacionais}

Conforme dados constatados no aspecto da inclusão escolar, uma das maiores incidências é sobre o direito ao profissional de apoio para seus filhos, profissional este que tem como objetivo auxiliar os alunos incluídos no que se refere as questões pedagógicas e de autonomia, visando o acompanhamento dos mesmos no ensino. Portanto, cabe a este profissional acompanhar o desenvolvimento do seu aluno, adaptar materiais de acordo com as necessidades específicas e incluir o aluno para que o mesmo sinta-se pertencente a turma em que encontra-se matriculado.

Neste sentido, iremos explanar as legislações:

Segundo o Estatuto da Criança e do Adolescente - ECA em seu Art. 69, o adolescente tem direito à profisssionalização e à proteção no trabalho, observados o seguinte aspecto, entre outros, no inciso II que se refere a capacitação profissional adequada ao mercado de trabalho.

Porém a Lei de Diretrizes e Bases da Educação Nacional - LDB - Lei no 9.394 de 20/12/96 destina o Capítulo V inteiramente à educação especial, definindo-a no Art. 58 como uma "modalidade de educação escolar, oferecida preferencialmente na rede regular de ensino, para educandos que apresentam necessidades especiais".

Temos a consciência que hoje a busca por uma escola inclusiva é o que se tem mais tentado realizar, mas ainda nos deparamos com a dualidade.

Temos ainda que salientar que para o aluno incluído no Ensino Regular, Resolução $\mathrm{n}^{\mathrm{o}} 4$, de 2 de outubro de 2009, que Institui Diretrizes Operacionais para o Atendimento Educacional Especializado na Educação Básica, modalidade Educação Especial. O trabalho realizado no contra turno é oferecido a todos de acordo com as necessidades. Neste sentido a legislação sobre o Atendimento Educacional Especializado - AEE tem a seguinte função de perpassar todos os níveis, etapas e todas as modalidades da educação básica e superior e disponibiliza recursos próprios desse atendimento.

Art. $4^{\circ}$ Para fins destas diretrizes considera-se público-alvo do AEE:

I - Alunos com deficiência: aqueles que têm impedimentos de longo prazo de natureza física, intelectual, mental ou sensorial.

II - Alunos com transtornos globais do desenvolvimento: aqueles que apresentam um quadro de alterações no desenvolvimento neuropsicomotor, comprometimento nas relações sociais, na comunicação ou estereotipias 
motoras. Incluem-se nessa definição alunos com autismo clássico, síndrome de Asperger, síndrome de Rett, transtorno desintegrativo da infância (psicoses) e transtornos invasivos sem outra especificação.

III - Alunos com altas habilidades/superdotação: aqueles que apresentam um potencial elevado e grande envolvimento com as áreas do conhecimento humano, isoladas ou combinadas: intelectual, liderança, psicomotora, artes e criatividade.

Temos também a função do trabalho desenvolvido pelo professor nesta modalidade, ou seja, o Art. 13. São atribuições do professor do Atendimento Educacional Especializado:

I - identificar, elaborar, produzir e organizar serviços, recursos pedagógicos, de acessibilidade e estratégias considerando as necessidades específicas dos alunos público-alvo da Educação Especial;

II - elaborar e executar plano de Atendimento Educacional Especializado, avaliando a funcionalidade e a aplicabilidade dos recursos pedagógicos e de acessibilidade;

III - organizar o tipo e o número de atendimentos aos alunos na sala de recursos multifuncionais;

IV - acompanhar a funcionalidade e a aplicabilidade dos recursos pedagógicos e de acessibilidade na sala de aula comum do ensino regular, bem como em outros ambientes da escola;

$\mathrm{V}$ - estabelecer parcerias com as áreas intersetoriais na elaboração de estratégias e na disponibilização de recursos de acessibilidade;

VI - orientar professores e famílias sobre os recursos pedagógicos e de acessibilidade utilizados pelo aluno;

VII - ensinar e usar a tecnologia assistiva de forma a ampliar habilidades funcionais dos alunos, promovendo autonomia e participação;

VIII - estabelecer articulação com os professores da sala de aula comum, visando à disponibilização dos serviços, dos recursos pedagógicos e de acessibilidade e das estratégias que promovem a participação dos alunos nas atividades escolares.

Em 2012 a Lei Ordinária Federal n ${ }^{\circ}$ 12.764, que instituiu a Política Nacional de Proteção dos Direitos da Pessoa com Transtorno do Espectro Autista, estabelecendo diversas diretrizes para sua consecução, tem em seu artigo $2^{\circ}$, o direito a acompanhante especializado, ou seja, este aspecto tal recorrido pelos pais, como um direito, encontra-se referendado na lei.

Outra legislação é a Lei Brasileira de Inclusão da Pessoa com Deficiência, (Lei n ${ }^{\circ}$ 13.146 de 06 de julho de 2015) que assegura e promove em condições de igualdade, o exercício dos direitos e das liberdades da pessoa com deficiência, visando à inclusão social e cidadania. No capítulo IV no direito a Educação, especificamente no artigo 27, temos a indicação que,

A educação constitui direito da pessoa com deficiência, assegurados sistema educacional inclusivo em todos os níveis e aprendizado ao longo de toda a vida, de forma a alcançar o máximo desenvolvimento possível de seus talentos e habilidades físicas, sensoriais, intelectuais e sociais, segundo suas características, interesses e necessidades de aprendizagem. 
Parágrafo único. É dever do Estado, da família, da comunidade escolar e da sociedade assegurar educação de qualidade à pessoa com deficiência, colocando-a a salvo de toda forma de violência, negligência e discriminação.

A referida investigação trata-se de um assunto específico, que é referente aos profissionais de apoio e que a legislação assegura em seu Art. 28, onde incumbe ao poder público assegurar, criar, desenvolver, implementar, incentivar, acompanhar e avaliar:

I - sistema educacional inclusivo em todos os níveis e modalidades, bem como o aprendizado ao longo de toda a vida;

II - aprimoramento dos sistemas educacionais, visando a garantir condições de acesso, permanência, participação e aprendizagem, por meio da oferta de serviços e de recursos de acessibilidade que eliminem as barreiras e promovam a inclusão plena;

III - projeto pedagógico que institucionalize o atendimento educacional especializado, assim como os demais serviços e adaptações razoáveis, para atender às características dos estudantes com deficiência e garantir o seu pleno acesso ao currículo em condições de igualdade, promovendo a conquista e o exercício de sua autonomia;

IV - oferta de educação bilíngüe, em Libras como primeira língua e na modalidade escrita da língua portuguesa como segunda língua, em escolas e classes bilíngües e em escolas inclusivas;

$\mathrm{V}$ - adoção de medidas individualizadas e coletivas em ambientes que maximizem o desenvolvimento acadêmico e social dos estudantes com deficiência, favorecendo o acesso, a permanência, a participação e a aprendizagem em instituições de ensino;

VI - pesquisas voltadas para o desenvolvimento de novos métodos e técnicas pedagógicas, de materiais didáticos, de equipamentos e de recursos de tecnologia assistiva;

VII - planejamento de estudo de caso, de elaboração de plano de atendimento educacional especializado, de organização de recursos e serviços de acessibilidade e de disponibilização e usabilidade pedagógica de recursos de tecnologia assistiva;

VIII - participação dos estudantes com deficiência e de suas famílias nas diversas instâncias de atuação da comunidade escolar;

IX - adoção de medidas de apoio que favoreçam o desenvolvimento dos aspectos linguísticos, culturais, vocacionais e profissionais, levando-se em conta o talento, a criatividade, as habilidades e os interesses do estudante com deficiência;

$\mathrm{X}$ - adoção de práticas pedagógicas inclusivas pelos programas de formação inicial e continuada de professores e oferta de formação continuada para o atendimento educacional especializado;

XI - formação e disponibilização de professores para o atendimento educacional especializado, de tradutores e intérpretes de Libras, de guias intérpretes e de profissionais de apoio;

XII - oferta de ensino de Libras, do Sistema Braille e de uso de recursos de tecnologia assistiva, de forma a ampliar habilidades funcionais dos estudantes, promovendo sua autonomia e participação;

XIII - acesso à educação superior e à educação profissional e tecnológica em igualdade de oportunidades e condições com as demais pessoas;

XIV - inclusão em conteúdos curriculares, em cursos de nível superior e de educação profissional técnica e tecnológica, de temas relacionados à pessoa com deficiência nos respectivos campos de conhecimento; 
$\mathrm{XV}$ - acesso da pessoa com deficiência, em igualdade de condições, a jogos e a atividades recreativas, esportivas e de lazer, no sistema escolar;

XVI - acessibilidade para todos os estudantes, trabalhadores da educação e demais integrantes da comunidade escolar às edificações, aos ambientes e às atividades concernentes a todas as modalidades, etapas e níveis de ensino;

XVII - oferta de profissionais de apoio escolar;

XVIII - articulação intersetorial na implementação de políticas públicas.

$\S 1^{\circ}$ - Às instituições privadas, de qualquer nível e modalidade de ensino, aplica-se obrigatoriamente o disposto nos incisos I, II, III, V, VII, VIII, IX, X, XI, XII, XIII, XIV, XV, XVI, XVII e XVIII do caput deste artigo, sendo vedada a cobrança de valores adicionais de qualquer natureza em suas mensalidades, anuidades e matrículas no cumprimento dessas determinações.

$\S 2^{\circ}-\mathrm{Na}$ disponibilização de tradutores e intérpretes de Libras a que se refere o inciso XI do caput deste artigo, deve-se observar o seguinte:

I - os tradutores e intérpretes de Libras atuantes na educação básica devem, no mínimo, possuir ensino médio completo e certificado de proficiência em Libras; (Vigência)

II - os tradutores e intérpretes de Libras, quando direcionados à tarefa de interpretar nas salas de aula dos cursos de graduação e pós-graduação, devem possuir nível superior, com habilitação, prioritariamente, em Tradução e Interpretação em Libras. (Vigência).

Como percebemos, as legislações são específicas e asseguram em termos legais todos os aspectos voltados a necessidade de fornecer os apoios necessários para que o processo de ensino e de aprendizagem ocorra da melhor maneira possível.

\section{Um estudo de caso que irá exemplificar o que estamos nos referindo na busca da inclusão escolar por sentir que o seu direito foi litigado}

Esta investigação é pautada pelos princípios éticos para investigações realizadas com seres humanos. Procurou-se ter em conta todos os cuidados necessários a uma pesquisa desta natureza, como a proteção da participante e dos profissionais envolvidos, garantindo a segurança do anonimato.

A escolha deste case foi devido a busca desta família pelos direitos da sua filha em ter profissional de apoio e pela disponibilidade para participar da referida investigação. No contato com a família foi estabelecido e assegurado o caráter anônimo da participação, a não divulgação das identidades e que o material será protegido de terceiros, não sendo permitido o acesso a quaisquer informações.

No dia da entrevista, a investigadora explicou a finalidade da investigação e explicou sobre os temas que seriam abordados, bem como que estavam seguindo os princípios éticos e de seriedade diante das respostas e acesso aos documentos que a família dispunha. 
As informações aqui apresentadas preservam o sigilo, não havendo dados que permitam identificar as famílias e nem acriança, por envolver situações complexas e delicadas, em que o bom senso, sigilo e cuidado com a emissão de juízos de valor facilitam a investigação, quando ocorre a confiança na investigadora.

Para Molina e Dias (2003), a ética na pesquisa não engloba apenas estudos de caráter invasivo em seres humanos, mas é baseada principalmente no intuito de melhorar a qualidade de vida dos indivíduos, isolada ou coletivamente. Nesta investigação, a aluna é um sujeito ativo do próprio processo de humanização e de direitos sociais.

A ética na pesquisa é um procedimento metodológico que não pode ser ignorado pelo pesquisador. A pesquisa envolve aspetos éticos, legais e morais. A atitude ética do pesquisador é um critério que se faz presente durante todo processo da pesquisa.

Neste caso buscou-se inicialmente, analisar todas as avaliações que a referida família tem sobre o diagnóstico da sua filha. Deparamo-nos, neste processo, com várias avaliações e documentos de diferentes profissionais.

Nesta investigação, a investigadora analisou os documentos avaliativos, parecer médico e documentos oficiais sobre o processo inclusivo para a solicitação do professor de apoio.

Iniciaremos esclarecendo que a referida aluna realizou o teste genético, onde caracteriza o seu laudo como Síndrome do X Frágil - SXF.

Quando recorremos a legislação, a Lei No 17.681, de 17 de setembro de 2013 que institui a Política Estadual de Proteção dos Direitos da Pessoa com Síndrome do X Frágil, nos deparamos com o Art. $3^{\circ}$. São direitos da pessoa com Síndrome do X Frágil, no IV que se refere ao acesso. Parágrafo único. Em casos de comprovada necessidade, a pessoa com Síndrome do X Frágil incluída nas classes comuns de ensino regular, nos termos do inciso IV do Art. $2^{\circ}$, terá direito a acompanhante especializado.

Já constatado a SXF com mutação completa, recorremos ao laudo médico que nos esclarece que a menor apresenta autismo grau leve e SXF, o que garante em lei o acompanhante especializado para a classe comum do Ensino Regular.

No laudo médico podemos também observar que o médico solicita profissional de apoio.

Ainda em relação ao processo avaliativo, temos o parecer sobre as questões relacionadas a parte intelectual e nos deparamos com o seguinte parecer sobre teste Escala Wechsler de Inteligência para Crianças - WISC IV, que deu como resultado em uma das áreas 
como inferior a média e ainda que sugere o profissional de apoio para auxiliar no processo de aprendizagem.

A família ainda recorre a avaliação neuropsicológica, relata que em decorrência do quadro clinico indica-se professor de apoio para favorecer a aquisição de conteúdos relacionados a aprendizagem e socialização.

Quando a Avaliação Psicoeducacional faz referência a necessidade de novas avaliações no Centro de Acompanhamento Psicossocial - CAPS também faz a menção sobre a necessidade de professor de apoio.

Com a frequência na Sala de Recursos Multifuncional, foi constatado que a aluna não deveria ser retida naquele ano escolar, pois demonstrou avanços mesmo não tendo o profissional de apoio conforme a família vinha solicitando.

O professor de apoio também foi indicado por mais um profissional que desenvolve um trabalho terapêutico com a aluna, enfatizando que a aluna apresenta conteúdos defasados é imprescindível professor auxiliar com o objetivo de uma educação de qualidade, para sanar os conteúdos defasados, melhorar a qualidade de atenção e a busca por autonomia.

Diante de todos estes dados, a família ainda sente a necessidade em recorrer ao Ministério Público, solicitando professor de apoio para a sua filha. O Ministério Público solicita a Secretária Estadual de Educação um parecer por ser responsável por está pasta.

O parecer da Secretaria Estadual de Educação, em resposta a solicitação de profissional de apoio foi que a aluna não necessita de professor de apoio ou auxiliar por não apresentar falta de autonomia e não entra no mérito das questões pedagógicas.

Como percebemos nos documentos e pareceres profissionais, não temos dúvida quanto ao diagnóstico da referida aluna, inclusive inúmeros pareceres solicitando o profissional de apoio para o acompanhamento da aluna no Ensino Regular.

A legislação é muito direta ao que se tem direito o aluno incluído e o que acontece então quando percebemos que a referida aluna tem o seu direito litigado?

A mãe solicitou a revisão e não obteve retorno até a metade do ano letivo, sendo que faltam poucos meses para o término das aulas em 2019 e a referida aluna ficou quase todo o ano letivo sem o professor de apoio.

Após este parecer, a entidade mantenedora ofereceu uma estagiária para auxiliar a aluna. 


\section{Conclusão}

Diante de todos os aspectos levantados neste estudo de caso, conseguimos perceber que os profissionais indicam a necessidade do professor de apoio, a legislação ampara tal situação e o Ministério Público recorre a um parecer técnico à Secretaria Estadual de Educação para a concretização da necessidade ou não do profissional de apoio, sendo que este órgão justifica que não percebe a necessidade deste profissional devido a aluna demonstrar autonomia no ambiente escolar.

O que nos parece é que em nenhum momento a solicitação de um professor de apoio foi para auxiliar a aluno no que se refere as questões de vida diária e de autonomia, mas sim foi amplamente justificado que o maior objetivo deste profissional seria para auxiliá-la no processo de apropriação aos conhecimentos abordados pela instituição de ensino.

Também pudemos perceber que a aluna tem bastantes recursos a ela oferecidos em relação a atividades de contra turno e está amplamente amparada pela legislação quando o assunto é direito ao profissional de apoio, para apoiá-la nas questões pedagógicas.

$\mathrm{Na}$ área educacional seria uma mais valia para a aluna ter acesso a uma professora de apoio para mediar os aspectos pedagógicos sempre que a aluna encontrasse dificuldades no processo de ensino e de aprendizagem.

Ao reportar-me aos objetivos propostos nesta investigação, compreendendo o motivo da família ter recorrido à justiça a um determinado aspecto garantido pela legislação, isso nos evidencia que este aspecto pode não ser garantido a todos. Devido a este fator é que a família recorre na busca pelo seu direito. Quanto aos objetivos específicos é possível identificar que a legislação brasileira realmente assegura o professor de apoio e também em compreender que a família e a escola percebem a necessidade de tal profissional quando o assunto são os aspectos pedagógicos. O Ministério Público por sua vez busca a entidade responsável para se ter um parecer técnico e o mesmo vem com uma justificativa que em nenhum momento foi indicado com uma necessidade sentida pelos profissionais que desenvolvem o seu trabalho com a aluna.

Enquanto pesquisadores nos deparamos com o aspecto legal onde essa justificativa não aparece como determinante, pois percebemos que temos no Brasil inúmeras legislações assegurando o que estava sendo solicitado e quando pensamos na educação, considerada como um Direito Humano, percebemos que neste estudo de caso, a aluna não teve respeitado o seu direito, assegurado legalmente. 
A aluna não conseguiu ter acesso ao professor de apoio, teve uma estagiária para lhe auxiliar apenas nos últimos meses de estudo, a preocupação maior fica em relação ao sistema educacional brasileiro, pois no próximo ano letivo a aluna estará entrando em uma nova fase escolar que é o Ensino Fundamental - Anos Finais - organizado por matérias divididas por minutos e tendo uma diversidade de até cinco professores ao dia com matérias distintas.

Nesta direção fica a maior preocupação se tudo isso seria necessário se temos este aspecto amparado na legislação sobre a legalidade no que se refere ao professor de apoio para os alunos incluídos? A resposta seria não, se isso realmente estivesse ocorrendo na prática, independentemente se a aluna tem ou não autonomia, pois recorremos apenas às questões pedagógicas.

Desta forma, explicito a necessidade de futuros estudos em relação aos dados de quantos alunos incluídos tem professor de apoio no Brasil, desta forma poderemos analisar de uma forma amplia se este direito está sendo cumprido ou litigado no Brasil.

Quando pensamos em inclusão escolar temos que compreender que somos diferentes, temos que ter estratégias de trabalho educacionais distintas e somente desta forma conseguiremos pensar na escola de forma não homogênea, onde o respeito pelas diferenças esteja no ponto principal. Ou melhor, ainda que os alunos tenham direito em estar nos espaços escolares e se apropriarem dos conhecimentos ali ensinados de acordo com as necessidades respeitadas, seja elas de forma mais ampla ou mais individualizada.

\section{Referências:}

Ainscow, M., Booth, T. y Dyson, A. (2006). Improving schools, developing inclusion. Londres: Routledge.

Brasil. Lei Brasileira de Inclusão da Pessoa com Deficiência, Lei n ${ }^{\circ} 13.146$ de 06 de julho de 2015.

Brasil. Política Nacional de Proteção dos Direitos da Pessoa com Transtorno do Espectro Autista. Lei n. 12.764, de 27 de dezembro de 2012.

Brasil. Institui a Política Estadual de Proteção dos Direitos da Pessoa com Síndrome do X Frágil. Lei No 17.681, de 17 de setembro de 2013.

Dessen, M. A. \& Polonia, A. C. (2007). A Família e a Escola como contextos de desenvolvimento humano. Disponível em www.scielo.br/paideia

Erickson, F. (1986). Qualitative methods in research on teaching. In M. C. Wittrock (Ed.), Handbook of research on teaching. Pp. 119-161. Nova Iorque: MacMillan. 
Guerra, I. C.(2006). Pesquisa Qualitativa e Análise de Conteúdo. Lisboa: Principia.

Flick, U. (2004). Uma introdução à pesquisa qualitativa. 2. Ed. Porto Alegre: Bookman.

Miranda, M. G. (1989). Psicologia Social. O homem em movimento. $8^{\mathrm{a}}$ edição. Ed. Brasiliense, São Paulo

Molina, R. e Dias, E. (2003). Iniciação em pesquisa científica: Manual para profissionais e estudantes das áreas da saúde, ciências biológicas e humanas. Edupe.

ONU; UNESCO. (2006) Plan de Acción: Programa Mundial para La Educación em Derechos Humanos - Primera etapa. Nueva York y Genebra, 61.

Pando Ballesteros, Ma Paz; Muñoz Ramírez, Alicia y Garrido Rodríguez, Pedro (dirs. y eds.) (2016): Pasado y Presente de los Derechos Humanos. Mirando al Futuro. Ed. Los Libros de la Catarata. Madrid

Pinto, A. V. (1989) Ciência e existência problemas filosóficos da pesquisa científica. $2^{\mathrm{a}}$ Ed. Rio de Janeiro: Paz e Terra.

Pujolás, P. (2006). Aulas inclusivas y aprendizaje cooperativo. A tu Salud, 55, Pp. 20-27.

Saviani, D. (2003) Pedagogia histórico-crítica: primeiras aproximações. Campinas, SP: Autores Associados.

Saviani, D. (2005). Pedagogia hisórico-crítica: primeiras aproximações. São Paulo: Autores associados.

UNESCO (1999). Los siete saberes necessários para la educación del futuro. Madrid: Santillana.

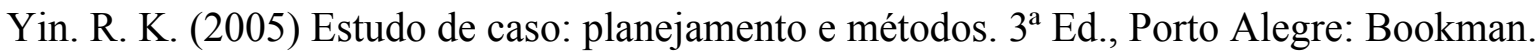

